\title{
Oportunidades para hacer más ágil el comercio agropecuario México-Estados Unidos
}

\author{
Steven Zahniser
}

U.S. Department of Agriculture, Economic Research Service

\author{
Adriana Herrera Moreno \\ Arturo Calderón Ruanova ${ }^{1}$ \\ Secretaria de Agricultura, Ganadería, Desarrollo Rural, Pesca y Alimentación
}

Recepción: 28 de noviembre de 2016 Aceptación: 24 de abril de 2017

Resumen Este artículo explora algunas maneras de facilitar el comercio agropecuario México-Estados Unidos, enfocándose en los procesos y procedimientos en la frontera que rigen este comercio. Se llevaron a cabo 80 entrevistas en ambos países con expertos del sector privado, el gobierno y la academia. Con la información recopilada en estas entrevistas y la obtenida de fuentes públicas, se identificaron seis áreas de oportunidad para hacer más ágil el comercio agropecuario México-Estados Unidos: aspectos relacionados con el sector agropecuario respecto al tránsito y la inspección en la frontera; sistemas de predespacho y de preinspección, e instalaciones de inspección conjunta; un mayor desarrollo de los sistemas de inspección basados en riesgo; anticipación de nuevas instalaciones de transporte y nuevas rutas de envío; actividades complementarias para las Ventanillas Únicas, y creación de vías formales para la innovación reguladora.

PALABRAS CLAVE: México, Estados Unidos, agropecuario, comercio, frontera, regulaciones, TLCAN.

Abstract This report explores ways to facilitate U.S.-Mexico agricultural trade by focusing on the border processes and procedures that govern this trade. About 80 interviews were conducted with experts from the private sector, government, and academia in the United States and Mexico. Based on information collected during these interviews and information

Los otros miembros del equipo de investigación fueron Sahar Angadjivand, Francisco Javier Calderón Elizalde, Linda Calvin, César López Amador, Nicolas Fernández López López, Jorge Alberto Valdes Ramos, Rosalinda Flores Camacho, y Ximena Juárez Gómez. 
drawn from public sources, six areas of opportunity were identified for making U.S.-Mexico agricultural trade more agile: agriculture-related aspects of border crossings and inspections; pre-clearance and pre-inspection systems and joint inspection facilities; further development of risk-based inspection systems; preparations in advance for new transportation facilities and shipment routes; complementary activities for Single Window Environments; and creation of formal avenues for regulatory innovation.

KEY WORDS: Mexico, United States, agriculture, trade, border, regulations, NAFTA.

\section{Agradecimientos}

Agradecemos a Enrique Sánchez Cruz, director jefe del Servicio Nacional de Sanidad, Inocuidad y Calidad Agroalimentaria (Senasica) de la Secretaría de Agricultura, Ganadería, Desarrollo Rural, Pesca y Alimentación (Sagarpa); Raúl Urteaga Trani, titular de la Coordinación General de Asuntos Internacionales (CGAI) de la Sagarpa; Lloyd Harbert, Ydun Donahoe, Alicia Hernández y Neil Mikulski, del Servicio Agrícola del Exterior del Departamento de Agricultura de los Estados Unidos (U.S. Department of Agriculture, Foreign Agriculutural Service, USDA/ FAS); Lynn Alfalla, del Servicio de Inspección de Salud Agropecuaria (Animal and Plant Health Inspection Service, APHIS) del UsDA; Belem Avendaño, de la Universidad Autónoma de Baja California; John Dyck, del Servicio de Investigación Económica (Economic Research Service, ERs) del USDA; Bucky Gwartney, del Servicio de Comercialización Agrícola (Agricultural Marketing Service, AMs) del UsDA; Luis Ribera, de Texas A \& M University, y Bruce Ross, Glenn Bass y Peter Fox, de la Oficina de Asuntos Regulatorios de la Administración de Alimentos y Medicamentos de Estados Unidos (Food and Drug Administration, FDA), por sus valiosas revisiones por pares. También agradecemos a Dan Berman, jubilado de USDAFAS; Peter Olson de USDA/FAS, y Erik Dohlman, William Liefert y Andrew Muhammad de USDA/ERS, por sus consejos y comentarios, así como a Rosalinda Flores Camacho y Ximena Juárez Gómez de Senasica, por facilitar las entrevistas en la región fronteriza. Algunos hallazgos en este artículo fueron obtenidos a través de actividades financiadas por la Subvención No. 58-3000-3-0064 del Programa de Mercados Emergentes del USDA/FAs. Por último, gracias especialmente a Dale Simms y Mary Conley, de USDA/ERs, y al personal de la revista Carta Económica Regional, por la edición del artículo. 


\section{Introducción}

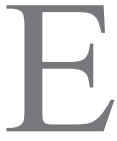

n el marco del Tratado de Libre Comercio de América del Norte (TLCAN), México y Estados Unidos eliminaron gradualmente todos los aranceles y cuotas que rigieron el comercio agropecuario bilateral durante un período de transición de 14 años, que abarcó desde el 1 de enero de 1994 al 1 de enero de $2008 .^{2}$ Antes de la entrada en vigencia del TLCAN, este comercio se sujetaba a aranceles de importación por un promedio de 5.7 \% sobre una base ponderada por el comercio (Burfisher, House \& Langley, 1992), ${ }^{3}$ y el comercio bilateral agropecuario enfrentaba algunos obstáculos. Por ejemplo, México requería certificados de importación para un subconjunto de productos básicos que correspondía aproximadamente a una cuarta parte del valor de las exportaciones agropecuarias de Estados Unidos a México (Link \& Zahniser, 1999), mientras que Estados Unidos aplicaba aranceles de importación estacionales más altos en frutas y hortalizas mexicanas cuando competían con las estadounidenses.

En tanto que México y Estados Unidos liberalizaban su comercio bilateral, seguían cooperando en temas sanitarios, fitosanitarios y en otras áreas que afectaban al sector agropecuario. Por ejemplo, se negociaron protocolos fitosanitarios que permitieron la exportación de aguacate mexicano a Estados Unidos, además de una campaña coordinada por los gobiernos de los tres países miembros del TLCAN que estableció un enfoque armonizado para la mitigación de los riesgos asociados con la encefalopatía espongiforme bovina (ЕЕB). Juntas, la liberalización del comercio y la mayor cooperación regulatoria propiciaron un aumento significativo en el comercio agropecuario entre México y Estados Unidos. Entre 1993 y 2015, las exportaciones agropecuarias del primero al segundo aumentaron de 2.7 a 21.0 miles de millones de dólares, mientras que las exportaciones agropecuarias de Estados Unidos a México se incrementaron de 3.6 a 17.7 miles de millones de dólares (gráfica 1). Descontando la inflación, este crecimiento en el comercio agropecuario bilateral representó un aumento de $408 \%$ en las exportaciones de México y de $222 \%$ en las exportaciones de Estados Unidos. ${ }^{4}$

2 Canadá, el otro país miembro del TLCAN, también participó en la liberalización del comercio intrarregional, aunque el TLCAN exentó algunos aspectos del comercio agropecuario Estados Unidos-Canadá y México-Canadá de esta liberalización. El TLCAN también permite a los países miembros continuar aplicando sus leyes nacionales en materia de antidumping y medidas compensatorias, y acuerdos para suspender casos específicos de prácticas comerciales desleales han dado lugar a la imposición de nuevas restricciones comerciales, que incluyen precios mínimos para las importaciones de tomates frescos de Estados Unidos desde México y precios mínimos y límites cuantitativos para la importación de azúcar a Estados Unidos desde México.

3 Se estiman en $5.7 \%$ los impuestos a las exportaciones agropecuarias tanto de Estados Unidos a México como de México a Estados Unidos, calculados a partir de datos de aranceles para 1991 y pesos de 1989.

4 Se utilizaron deflactores implícitos de precios para el producto interno bruto (PIB) de Estados Unidos 
GRÁFICA 1. La liberalización del comercio y la cooperación regulatoria han facilitado el crecimiento del comercio agropecuario entre México y Estados Unidos

25

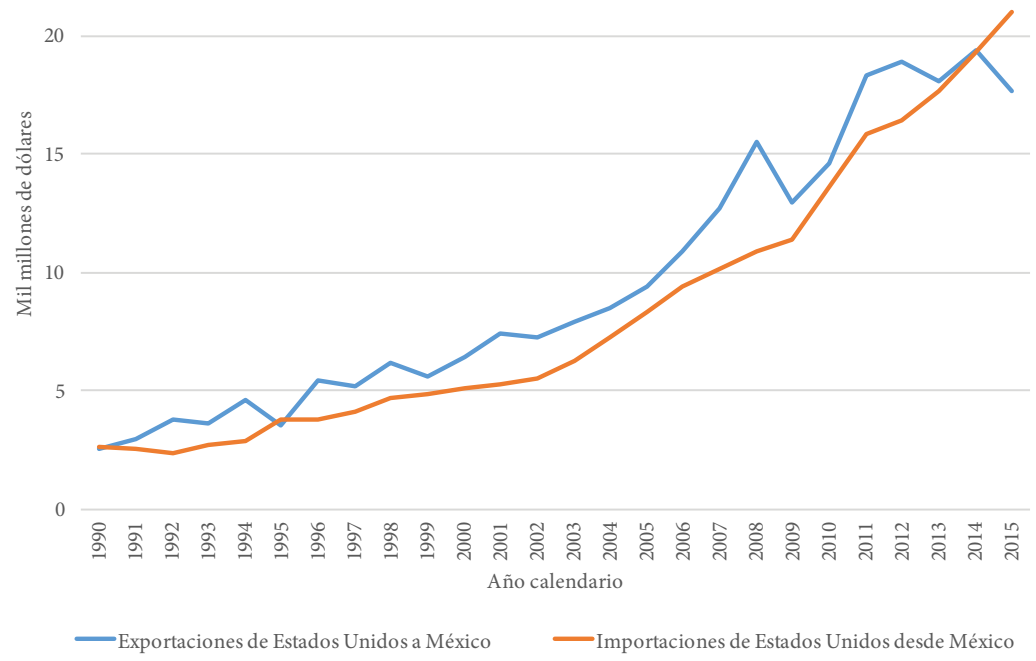

Fuente: U.S. Department of Commerce, Census Bureau, Foreign Trade Statistics, citado por USDA/FAS (2016).

Con la plena aplicación de las disposiciones del TLCAN en el área de liberalización comercial, México y Estados Unidos deben buscar medios adicionales a la eliminación de aranceles y cuotas para fomentar un mayor crecimiento del comercio agropecuario bilateral. La mejora de la infraestructura fronteriza es un enfoque para hacer frente a este reto, pero a menudo requiere una inversión considerable de tiempo y dinero.

Otra manera de fomentar un mayor crecimiento del comercio agropecuario México-Estados Unidos es modificar los procedimientos fronterizos de manera que agilicen el comercio para que los productos crucen la frontera con mayor rapidez y facilidad. Novy (2013) encontró que la caída de los costos de transacción ha sido un factor clave para el crecimiento a largo plazo del comercio México-Estados Unidos: el arancel equivalente en costos de transacción que afecta el comercio bilateral agropecuario y no agropecuario se redujo de $96 \%$ en 1970 a $33 \%$ en 2000. Esta reducción explica aproximadamente el $57 \%$ del crecimiento del comercio bilateral durante este período. En un estudio sobre las importaciones de Estados Unidos y el

(U.S. Department of Commerce, Bureau of Economic Analysis, 2016) para ajustar los valores nominales del comercio. 
equilibrio entre el transporte aéreo y el marítimo, Hummels y Schaur (2012) estiman que cada día en tránsito equivale a un arancel ad valorem de entre 0.6 y $2.3 \%{ }^{5}$

\section{Enfoque de investigación}

El equipo de investigación estuvo conformado por especialistas en comercio agropecuario México-Estados Unidos y en medidas sanitarias, fitosanitarias y de seguridad alimentaria de tres agencias de ambos gobiernos:

- Servicio de Investigación Económica (Economic Research Service, ERs) del Departamento de Agricultura de los Estados Unidos (Department of Agriculture, USDA).

- Servicio Nacional de Sanidad, Inocuidad y Calidad Agroalimentaria (Senasica) de la Secretaría de Agricultura, Ganadería, Desarrollo Rural, Pesca y Alimentación (Sagarpa).

- Coordinación General de Asuntos Internacionales (CGAI) de la Sagarpa.

Para recabar ideas de cómo hacer más ágil el comercio agropecuario bilateral, el equipo de investigación llevó a cabo alrededor de 80 entrevistas, la gran mayoría de ellas realizadas en forma conjunta por al menos un miembro mexicano y un estadounidense del equipo de investigación.

Las entrevistas se centraron en tres temas principales: 1) los procesos y procedimientos que rigen los envíos agropecuarios transfronterizos; 2) el desarrollo y la armonización de sistemas operativos homólogos (similares) de los gobiernos de México y Estados Unidos, y 3) la cooperación intergubernamental. Se pidió a los entrevistados identificar los procesos transfronterizos que significan cuellos de botella por las limitaciones de inspección, porque son redundantes o por su poco valor, significado o importancia. Dada la relevancia de los costos de transporte por carretera del comercio agropecuario bilateral, se abordaron los problemas de transportación por este medio en algunas entrevistas aun cuando tanto el USDA como la Sagarpa tienen poca injerencia en su regulación.

Para llevar a cabo entrevistas personales y obtener información de primera mano acerca de la movilización de productos agropecuarios en la frontera México-Estados Unidos, el equipo de investigación estudió tres regiones fronterizas:

- Nogales, Arizona, y Nogales, Sonora (21-23 de julio de 2014).

- Laredo, Texas, y Nuevo Laredo, Tamaulipas (11-13 de agosto de 2014).

- San Diego (Otay Mesa), California, y Tijuana, Baja California (22 y 25-26 de agosto de 2014).

5 Esta estimación no refleja el comercio México-Estados Unidos, donde las modalidades de transporte más comunes son el carretero y el ferroviario. 
Estas regiones fueron seleccionadas por su diversidad geográfica e importancia para el comercio agropecuario México-Estados Unidos. Los dos Laredos conforman el principal punto de entrada y salida del comercio agropecuario México-Estados Unidos (cuadro 1). Nogales ocupa el quinto lugar en exportaciones agropecuarias de Estados Unidos a México y el segundo en este tipo de exportaciones de México a Estados Unidos. Durante el invierno y la primavera, Nogales es el punto más importante para la exportación de frutas y hortalizas mexicanas a Estados Unidos. La región Tijuana/San Diego ocupa el cuarto lugar en las exportaciones agropecuarias de Estados Unidos a México y el tercero en estas mismas exportaciones mexicanas a Estados Unidos, principalmente frutas y hortalizas. En conjunto, por estos tres puntos salieron el $87 \%$ de las exportaciones agropecuarias de México a Estados Unidos y el 69 \% de las estadounidenses a México durante el período 2012-2014.

CUADRO 1. Comercio agropecuario México-Estados Unidos por distrito de aduana: promedios anuales, 2013-2015

\begin{tabular}{|c|c|c|c|c|c|c|c|}
\hline 莡 & $\begin{array}{c}\text { Distrito de } \\
\text { aduana EE.UU. }\end{array}$ & $\begin{array}{l}\text { Exportaciones } \\
\text { a México }\end{array}$ & $\begin{array}{l}\text { Partici- } \\
\text { pación }\end{array}$ & 荬 & $\begin{array}{c}\text { Distrito de } \\
\text { Aduana EE.UU. }\end{array}$ & $\begin{array}{l}\text { Importaciones } \\
\text { desde México }\end{array}$ & $\begin{array}{l}\text { Partici- } \\
\text { pación }\end{array}$ \\
\hline & $\begin{array}{l}\text { Todos los } \\
\text { distritos }\end{array}$ & $\begin{array}{c}\text { Millones de } \\
\text { dólares } \\
18,393\end{array}$ & $\begin{array}{l}\text { Por } \\
\text { ciento } \\
100\end{array}$ & & $\begin{array}{l}\text { Todos los } \\
\text { distritos }\end{array}$ & $\begin{array}{c}\text { Millones de } \\
\text { dólares } \\
19,315\end{array}$ & $\begin{array}{c}\text { Por } \\
\text { ciento } \\
100\end{array}$ \\
\hline 1 & Laredo, Texas & 10,831 & 59 & 1 & Laredo, Texas & 10,469 & 54 \\
\hline 2 & El Paso, Texas & 2,491 & 14 & 2 & Nogales, Arizona & 3,606 & 19 \\
\hline 3 & $\begin{array}{l}\text { New Orleans, } \\
\text { Louisiana }\end{array}$ & 1,857 & 10 & 3 & $\begin{array}{l}\text { San Diego, } \\
\text { California }\end{array}$ & 2,675 & 14 \\
\hline 4 & $\begin{array}{l}\text { San Diego, } \\
\text { California }\end{array}$ & 1,596 & 9 & 4 & El paso, Texas & 1,337 & 7 \\
\hline 5 & Nogales, Arizona & 1,035 & 6 & 5 & $\begin{array}{l}\text { Detroit, } \\
\text { Michigan }\end{array}$ & 0.122 & 1 \\
\hline & Otros distritos & 582 & 3 & & Otros distritos & 1,107 & 6 \\
\hline
\end{tabular}

Fuente: U.S. Department of Commerce, Census Bureau, Foreign Trade Statistics, citado por USDA/FAS (2016)

Se hicieron algunas entrevistas adicionales y conferencias telefónicas a otras ciudades de México y Estados Unidos, entre ellas la Ciudad de México; Washington, D.C.; Celaya, Guanajuato; El Paso, Texas; Las Cruces, Nuevo México; Querétaro, Querétaro, y Weslaco, Texas.

Los esfuerzos para facilitar el comercio agropecuario México-Estados Unidos se dificultan debido a tres factores importantes. En primer lugar, el comercio agropecuario es un pez pequeño en el mar del comercio de mercancías entre ambos países. En 2015, los productos agropecuarios representaron solo el 7 \% de las expor- 
taciones de Estados Unidos a México y de las exportaciones de México a Estados Unidos. ${ }^{6}$ Como resultado de ello, muchas personas familiarizadas con el comercio bilateral de productos no agropecuarios y que podrían ayudar en los esfuerzos por agilizar el comercio de productos agropecuarios solo tienen un conocimiento limitado del comercio agropecuario.

En segundo lugar, muchas entidades gubernamentales, además del USDA y la Sagarpa, están involucradas en la regulación del comercio agropecuario bilateral. En Estados Unidos, las agencias clave son la Agencia de Aduanas y Protección Fronteriza (Customs and Border Protection, CBP) del Departamento de Seguridad Nacional (Department of Homeland Security, DHS) y la FDA. En México participan el Servicio de Administración Tributaria (SAT) de la Secretaría de Hacienda y Crédito Público (sHCP) y la Comisión Federal para la Protección Contra Riesgos Sanitarios (Cofepris) de la Secretaría de Salud. Dadas las atribuciones de las autoridades que regulan el comercio bilateral agropecuario, era necesario reflexionar de manera conjunta sobre los obstáculos que dificultan este comercio y las oportunidades para mitigarlos.

En tercer lugar, si se modificaran los procedimientos fronterizos para agilizar el comercio agropecuario bilateral se podría reducir la demanda de los servicios prestados por las empresas especializadas en logística en las fronteras. Por lo anterior, algunos prestadores de estos servicios pueden ser indiferentes ante tal necesidad. Algunos de los entrevistados no identifican ningún proceso o procedimiento en la frontera como duplicado, ineficaz o de poco valor. Muchos de quienes participantes en el comercio bilateral agropecuario dominan en gran medida estos procesos y procedimientos y se sienten cómodos con ellos.

\section{Temas que afectan el comercio bilateral agropecuario}

\section{La congruencia en los procedimientos normales de inspección}

Los entrevistados a lo largo de la frontera México-Estados Unidos mostraron una gran preocupación por la coherencia en la aplicación de los procedimientos normales de inspección, tanto en los puertos como a través del tiempo. Ambos gobiernos - a veces en forma conjunta con el sector privado- fomentan la coherencia en los procedimientos de inspección. Se mencionaron en las entrevistas actividades para mejorar en este aspecto como seminarios de capacitación para inspectores en

6 Estas proporciones se calcularon utilizando los datos comerciales del U.S. Department of Commerce, Census Bureau, Foreign Trade Statistics, citado por USDA/FAS (2016) (agropecuario) y U.S. Department of Commerce, Census Bureau (2016) (total). 
procedimientos de inspección cuarentenaria y sobre productos específicos, ejercicios para que funcionarios de diferentes organismos y gobiernos puedan enfrentar el reto en una crisis simulada y la supervisión directa a los inspectores por los funcionarios de las agencias.

Los sectores público y privado también trabajan juntos para fomentar una mejor comprensión dentro de la industria acerca de los requisitos que rigen el comercio agropecuario bilateral. Desde 2008, el Senasica organiza al menos una audiencia pública anual; en estas audiencias el sector privado, representantes en México de las agencias reguladoras de gobiernos extranjeros, proveedores de servicios y el público en general pueden externar sus preocupaciones e ideas de mejora. Además, el Consejo Mexicano de la Carne (Comecarne) y la Unión Nacional de Avicultores (UNA) han organizado talleres para agentes aduanales sobre los requisitos para la exportación de carne de Estados Unidos a México. De igual modo, la Secretaría de Economía, la Sagarpa y la Oficina Regional de América Latina de la FDA han llevado a cabo cuatro talleres sobre la Ley de Modernización de Seguridad Alimentaria de la FDA (Food Safety Modernization Act, FSMA-FDA) en 2013, en cuatro diferentes partes de México, y la oficina regional de la FDA realizó actividades de capacitación respecto a dos reglas propuestas por la FSM: la Regla de Frutas y Hortalizas y los Controles Preventivos para la Alimentación de los Seres Humanos (U.S.-México High Level Regulatory Coordination Council, 2013).

\section{Ventanilla Única}

La Ventanilla Única es un sistema que "permite a las partes involucradas en el comercio y transporte presentar información estandarizada, principalmente electrónica, en un único punto de entrada para cumplir con todos los requisitos reglamentarios relacionados con la importación, exportación, y tránsito" (World Customs Organization, 2015; traducción propia). Muchos países, entre ellos México y Estados Unidos, han puesto en marcha iniciativas de Ventanilla Única.

La Ventanilla Digital Mexicana de Comercio Exterior (VDMCE) - Ventanilla Única, para abreviar - ha estado en funcionamiento desde julio de 2012, cuando su uso se volvió obligatorio y se implementó el sistema en todas las Oficinas de Inspección de Sanidad Agropecuaria. La Ventanilla Única permite que toda la información requerida para una transacción de comercio internacional se pueda introducir en un portal de internet (figura 1) con el fin de reducir los costos de transacción y aumentar la competitividad de los exportadores mexicanos. La Ventanilla Única proporciona un sistema único para todas las agencias del Gobierno Federal mexicano que supervisan el comercio internacional. En cambio, las agencias reguladoras del USDA todavía tienen sistemas separados. 
FIGURA 1. Esquema general del funcionamiento de la Ventanilla Única

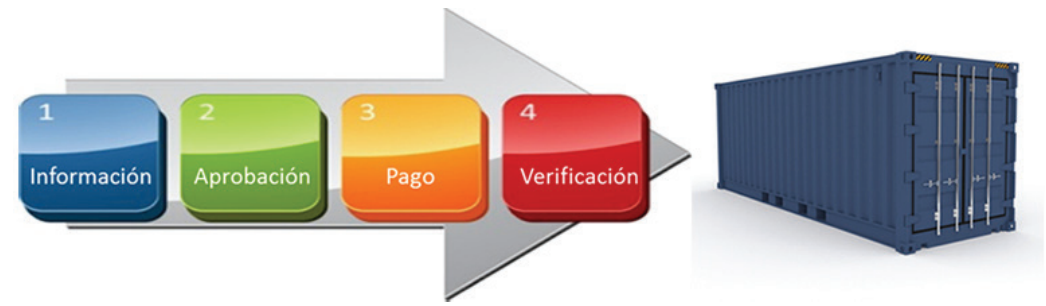

\begin{tabular}{|c|c|c|c|c|}
\hline $\begin{array}{l}\text { INFORMACIÓN: } \\
\text { El interesado ingresa en } \\
\text { www.ventanilla } \\
\text { unica.gob.mx y con su } \\
\text { Firma Electrónica } \\
\text { Avanzada (Fiel) registra } \\
\text { en línea la información } \\
\text { relacionada con la } \\
\text { importación, } \\
\text { exportación o transito de } \\
\text { mercancías. }\end{array}$ & $\begin{array}{l}\text { APROBACIÓN: } \\
\text { La información se } \\
\text { envía } \\
\text { electrónicamente } \\
\text { a las oficinas de } \\
\text { gobierno } \\
\text { correspondientes } \\
\text { para su } \\
\text { aprobación y } \\
\text { autorización. }\end{array}$ & $\begin{array}{l}\text { PAGO: } \\
\text { Los impuestos } \\
\text { se calculan y se } \\
\text { dictaminan } \\
\text { para proceder a } \\
\text { su cobro. }\end{array}$ & $\begin{array}{l}\text { VERIFICACIÓN: } \\
\text { Al presentar el } \\
\text { transportista un } \\
\text { formato simplificado, } \\
\text { el verificador de } \\
\text { aduana consulta la } \\
\text { información } \\
\text { mediante un } \\
\text { dispositivo digital } \\
\text { portátil y libera la } \\
\text { mercancía. }\end{array}$ & $\begin{array}{l}\text { INSPECCIÓN FÍSICA: } \\
\text { Una vez que la } \\
\text { documentación es } \\
\text { aprobada, el producto } \\
\text { está listo para su } \\
\text { inspección física. }\end{array}$ \\
\hline
\end{tabular}

Fuente: Adaptado de Gobierno de la República (2016).

La Ventanilla Única de Estados Unidos, conocida como Entorno Comercial Automatizado (Automated Commercial Environment, ACE), está programada para entrar en funcionamiento a finales de 2016 (figura 2). El uso obligatorio del ACE para la presentación de todos los manifiestos electrónicos inició el 1 de mayo de 2015, y el período de transición hacia su uso obligatorio para todas las entradas electrónicas y archivos electrónicos relacionados empezó el 1 de noviembre de 2015 y terminó el 23 de julio de 2016. La fecha prevista para el uso obligatorio del ACE para aquellas etapas faltantes a cargo de la СвP es enero de 2017, con una fecha todavía no prevista para su uso obligatorio en la presentación de datos por otras Agencias del Gobierno Asociadas (Partner Government Agency, PGA) (UsDHs/CBP, 2016b).

Los entrevistados expresaron un gran interés en la implementación y el perfeccionamiento de los dos sistemas de ventanilla única, como la interoperabilidad de VDMCE y ACE, así como permitir el acceso directo de los certificados electrónicos emitidos por los dos gobiernos de uno u otro sistema. En julio de 2015, la Sagarpa y el USDA firmaron una carta de intención para cooperar en el intercambio electrónico de certificados fitosanitarios y zoosanitarios (Sagarpa/Senasica, 2015). Además algunos usuarios de la Ventanilla Única piensan que todavía es posible mejorar el sistema. Por ejemplo, varios agentes aduanales identificaron la necesidad de desarrollar un sistema que permita la impresión de los certificados electrónicos y la corrección de errores en dichos certificados, ya sea en o cerca de la frontera. 
FIGURA 2. ¿Cómo funcionan el ACE y su Sistema de Imágenes de Documentos (Document Image System, DIS)?

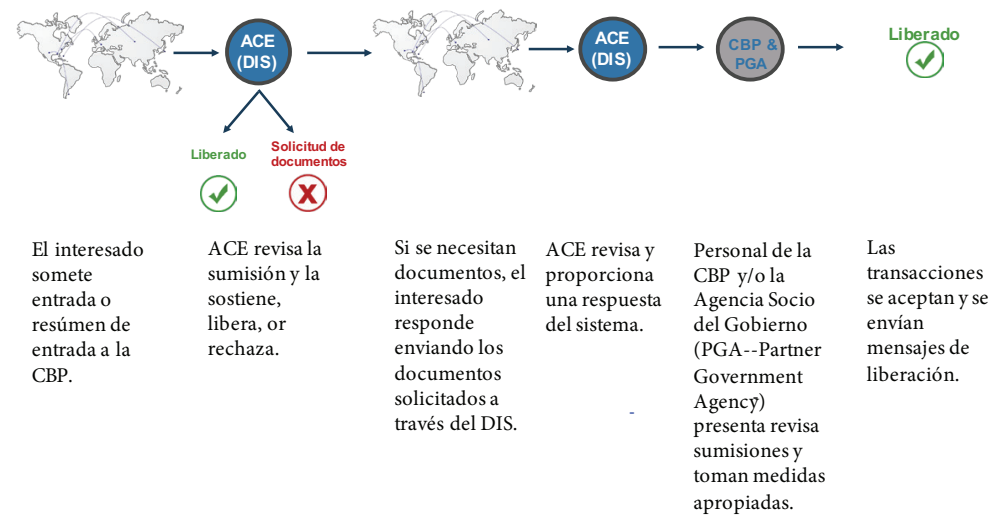

Fuente: Adaptado de USDHS/CBP (2016a)

\section{Organización administrativa e intercambio electrónico de información}

Los entornos de Ventanilla Única pueden servir como plataformas para la simplificación de los requisitos regulatorios y la reducción de las cargas administrativas en el comercio agropecuario. Con un sistema de Ventanilla Única los datos de un campo, en particular, se pueden introducir solo una vez, y el sistema reproducirá esos datos en los campos duplicados en todas las formas pertinentes dentro del sistema. La conversión de documentos de papel a documentos electrónicos puede reducir la cantidad de papeleo necesario.

Las exportaciones de queso de Estados Unidos a México ejemplifican las posibilidades de simplificación administrativa, pues deben cumplir con las normas de clasificación estadounidenses, y los envíos deben ir acompañados de diversas formas. Un exportador de queso de California entrevistado ofreció varias sugerencias para racionalizar estos requisitos:

- El Certificado de Exportación de Productos de Origen Animal del ApHis del USDA podría transitar hacia un formato electrónico.

- El requisito de Ventanilla Única de que sean presentadas las imágenes frontales y posteriores de los documentos con un periodo de vigencia podría ser eliminado para aquellos documentos que ya se han subido al sistema.

- El período de validez de ciertos permisos y certificados se podría ampliar.

- Se podrían combinar el Certificado Fisicoquímico de Análisis y el Certificado Microbiológico de Análisis de la Cofepris para formar uno único certificado. Cuestiones similares pueden aplicarse al comercio de ganado. Un veterinario 
del APHIs mostró como ejemplo la documentación necesaria para trasladar un cargamento de 18 novillos del estado de Chihuahua al puerto de entrada de Santa Teresa, Nuevo México. Si bien los documentos oficiales de la Sagarpa se pueden llenar electrónicamente, aún son necesarias las firmas originales. La copia física del formato muestra el origen de los animales, su salud, pruebas que se realizaron y otra información relevante del productor (números de identificación, información del arete, etc.). Otras formas certifican que los animales tienen prueba de tuberculosis, están libres de garrapatas y debidamente castrados; tienen el arete adecuado para la exportación, el certificado de no ser de raza pura Holstein Friesian (o sus cruzas) y que se cargarán en un camión limpio y desinfectado para su transporte.

Una vez que la Sagarpa certifica los documentos, los animales son llevados a un centro de inspección del USDA, donde un veterinario del APHIs llena formas para el USDA. Se requieren firmas originales para la Solicitud de Inspección y Aplicación de Inmersión (Application for Inspection and Dipping) y la Declaración de Importación (Declaration of Importation), y el veterinario del APHIS certifica que hay una marca " $M$ " en la cadera del animal y la fecha en que se le sumergió en la solución química. En total, la documentación acompañante ascendió a más de 15 páginas para este grupo de novillos importados.

\section{Papeleo incompleto o inadecuado}

Un desafío recurrente citado por los entrevistados es la preparación de la documentación precisa y completa para su presentación a las autoridades reguladoras. Por ejemplo, la Oficina del Servicio Agrícola del Exterior del usda en Monterrey, Nuevo León, estima que $95 \%$ de las solicitudes de asistencia que recibe la oficina de los exportadores agropecuarios de Estados Unidos están relacionadas con la presentación de documentación inexacta. Algunos fallos en la documentación probablemente sean resultado de una captura incorrecta de la información requerida. Estos errores pueden ser mitigados mediante el uso de cadenas de caracteres en que partes específicas de la cadena sirven como una doble comprobación de la validez de toda la cadena y evitando el uso de caracteres que se parecen entre sí (por ejemplo, utilizar el número 1 o la letra I, pero no ambos símbolos en el mismo sistema de identificación). De igual modo, el uso de motores de búsqueda puede ayudar a localizar coincidencias cercanas entre los identificadores reales y los identificadores que figuran en la documentación errónea.

\section{Un sistema integral de inspección basado en el riesgo}

Avanzar hacia la adopción de regímenes de inspección basados en ciencia en cuanto a riesgos sanitarios y fitosanitarios agilizaría el comercio agropecuario. En un sistema de inspección basado en el riesgo, la asignación de recursos a unas activida- 
des de inspección específicas, incluyendo el tipo y la frecuencia de las inspecciones, se guía por una evaluación de la probabilidad y gravedad de los riesgos asociados a los productos sujetos a inspección.

El Programa Nacional de Liberación Agrícola (National Agriculture Release Program, NARP), creado por el APHIS y operado conjuntamente por el APHIS y la CBP, "proporciona una metodología para la evaluación de las importaciones agropecuarias de gran volumen que presentan bajo riesgo de introducción de plagas y enfermedades de plantas en Estados Unidos" y se utiliza para facilitar la entrada de dichas importaciones procedentes de México y otros países (USDHS/CBP, 2014c, traducción nuestra). En el marco del NARP, los envíos comerciales de los productos aprobados por el mismo programa pueden ser inspeccionados con menos frecuencia en ciertas condiciones. Actualmente, el NARP solo se aplica a los envíos comerciales de frutas y hortalizas (frescos, congelados, procesados o semiprocesados) de ciertos países.

El programa mexicano Usuario Confiable (Ucon) permite que los importadores de carne aprobados sean inspeccionados con menos frecuencia. Los participantes están obligados inspeccionar el producto cárnico importado en la planta de destino por un médico veterinario oficial o un tercer especialista autorizado, y la planta de destino debe ser una planta Tipo Inspección Federal (TIF). Las plantas TIF son establecimientos de sacrificio y procesamiento certificados por el gobierno mexicano que cuentan con los más altos estándares sanitarios y los niveles más avanzados de procesamiento en el país. Los envíos en el marco del programa Ucon pueden ser rastreados con una etiqueta en todo momento. Si el programa Ucon fuera emparejado con un programa de exportadores de carne de confianza de Estados Unidos, se podrían definir las inspecciones de las que se dirigen a México en puntos específicos. Las relaciones reconocidas entre exportadores e importadores de confianza podrían permitir el establecimiento de protocolos sanitarios que faciliten más el comercio, como los que actualmente aplican solo a los traslados internos de la carne.

El Senasica está trabajando en un nuevo sistema operativo basado en el riesgo llamado Sistema Integral del Servicio de Inspección (SISI). El sISI es un sistema informático que utiliza información científica, estadística, legal y técnica para determinar la tasa de inspección para un producto específico, teniendo en cuenta diferentes variables de riesgo (Sagarpa/Senasica, 2013b). El sisi se aplicará a todos los productos (de origen vegetal, animal, acuícola y pesquero) reguladas por el Senasi$\mathrm{ca}$, incluyendo tanto productos nacionales como importados, a nivel de empresa y de producto. El sisi permitirá seleccionar los envíos sujetos a inspección mediante la identificación de mercancías de bajo riesgo y la facilitación de su entrada en México, incluyendo algunas que se consideren de bajo riesgo y que pueden ser inspeccionadas en destino. El sisı es muy similar a varios sistemas de inspección basados en el riesgo del gobierno estadounidense.

La Evaluación Predictiva Basada en el Riesgo para la Focalización Dinámica 
de Cumplimento de Importaciones (Predictive Risk-Based Evaluation for Dyanmic Import Compliance Targeting, PREDICT) es el sistema de la FDA "para ayudar a los inspectores de entrada para seleccionar los embarques de mayor riesgo para su examinación" y acelerar "el despacho de la carga de menor riesgo, pero solo si los datos exactos y completos son proporcionados por los importadores y los declarantes a la entrada" (USHHS/FDA, 2014b, traducción nuestra). La PREDICT hace una puntuación de riesgo particular para cada producto de importación (misma que se refiere como una "línea de entrada" [entry line]), utilizando minería automatizada de datos y el descubrimiento de patrones (USHHS/FDA/DIOP, 2012). Las puntuaciones de riesgo permiten que más líneas de entrada procedan en forma automática y proporciona a los inspectores de la FDA más información para decidir si se debe asignar un inspector de la FDA para una examinación adicional (USHHS/FDA, 2014b; USHHS/FDA/ DIOP, 2012).

La precisión en la puntuación de riesgo de la PREDICT depende de la calidad de la información proporcionada por los importadores y declarantes de entrada. La FDA indica que los transportistas a menudo presentan datos incompletos o inexactos, lo que retrasa la entrada de las mercancías importadas y desvía recursos de la FDA. La mejora en la calidad de los datos de las importaciones daría lugar a decisiones de admisibilidad más rápidas, más consistentes y mejor informadas. El personal de la FDA hizo hincapié en que la presentación de información completa y precisa durante el proceso de entrada es importante para la investigación de los brotes de enfermedades transmitidas por alimentos.

\section{Pre-despacho, pre-inspección e instalaciones conjuntas de inspección}

Pre-despacho (pre-clearance), pre-inspección e instalaciones conjuntas de inspección son elementos importantes en el diseño de algunas inspecciones agropecuarias a lo largo de la frontera México-Estado Unidos. Los términos "pre-despacho" y "pre-inspección" se utilizan a veces indistintamente con o sin un guion, pero los términos tienen sentidos distintos para algunas agencias gubernamentales, y el término "pre-despacho" puede tener sentidos diferentes entre agencias gubernamentales. Para la СBP, pre-inspección se refiere a una inspección oficial de Estados Unidos de un embarque en un país extranjero antes de la llegada del envío al puerto de entrada, mientras que pre-despacho se refiere a un viajero al que se concede permiso para entrar en Estados Unidos luego de que la persona y su equipaje son sometidos a los procesos de inmigración, aduanas e inspección agrícola en territorio extranjero, y no está sujeta a un procesamiento o un control de seguridad adicional a la llegada (USDHs/свр, 2014). Así, para la свр la pre-inspección de un envío no significa que ha sido autorizado a entrar en Estados Unidos; la autorización se obtiene más adelante, en el proceso de cruce de fronteras. Para el APHIS, 
pre-despacho se refiere a las inspecciones de los productos agrícolas que se realizan "en el extranjero bajo la supervisión directa de personal cualificado del APHIS, de acuerdo con las medidas fitosanitarias especificadas por la Agencia" (USDA/APHIS, 2015). En este artículo se describen las actividades de cada organismo utilizando su propia terminología.

El pre-despacho y la pre-inspección permiten que ciertos productos agropecuarios se sometan a las inspecciones (y los tratamientos de prevención de plagas, si es necesario) en su país de origen y luego ser importados en el marco de un proceso de vía rápida. Este enfoque puede beneficiar el comercio agropecuario de varias maneras. En primer lugar, la pre-inspección facilita la venta, donación o eliminación de los productos rechazados, ya que aún no han cruzado la frontera internacional. En segundo lugar, agiliza el cruce en la frontera internacional, lo que podría ampliar el mercado para los productos agropecuarios en general y los perecederos en particular. En tercer lugar se encuentran algunas actividades de tratamiento e inspección a cierta distancia del puerto de entrada, lo que aliviará la congestión fronteriza (Wilson, 2015). La pre-inspección se utiliza regularmente para las exportaciones de frutas y hortalizas de Estados Unidos a México (figura 3). Arreglos similares para los productos mexicanos se limitan actualmente a un programa de pre-inspección autorizada por el USDA/APHIS (2014) para los mangos enviados de México.

El Departamento de Agricultura del Estado de Arizona (ADA) inspecciona las frutas y legumbres importadas en Arizona, en nombre del AMs del usDa y en apoyo de los órdenes de comercialización estadounidenses. En el pasado, muchas de estas inspecciones se llevaron a cabo en instalaciones de pre-inspección operadas por concesionarios del sector privado en Nogales, Sonora. En 2010, sin embargo, estas actividades se trasladaron al otro lado de la frontera debido a preocupaciones de seguridad en México (Marizco, 2010; Wilkinson, 2010), un traslado que lamenta en general la industria de frutas y legumbres de Nogales por la pérdida de la eficiencia.

Estados Unidos y México han establecido una instalación conjunta de pre-inspección en Otay Mesa, Tijuana, Baja California, para ciertas importaciones de productos frescos mexicanos. Esta instalación, junto con la del puerto de entrada estadounidense de Otay Mesa, está diseñado específicamente para la entrada rápida de productos de bajo riesgo y alto volumen en el marco del NARP (Dibble, 2013). Una operación piloto de 180 días de esta instalación se puso en marcha en enero de 2016, después de lo cual se evaluará el programa y se decidirá si continúa o no.

La creación de instalaciones de inspección conjuntas puede impulsar la construcción o renovación de la infraestructura existente en la frontera. Las nuevas instalaciones en Otay Mesa, por ejemplo, cuentan con un laboratorio, un salón de refrigeración de última tecnología donde se pueden almacenar los perecederos si se requiere descargarlos durante el proceso de inspección, y un carril confinado 
directo al puerto de entrada a Estados Unidos (Dibble, 2016). De igual manera, las instalaciones de inspección conjuntas cuentan con seguridad a cargo de uno o más de los gobiernos nacionales y proporcionan un punto de acceso rápido para el personal autorizado.

En el caso del comercio bilateral de carne, no existe el proceso de pre-despacho. En lugar de ello los gobiernos de México y Estados Unidos reconocen la equivalencia en resultado y efecto de los procesos de inspección de cada país. Como parte de este enfoque, los procesadores deben estar certificados por sus respectivos gobiernos como elegibles para exportar y pueden ser sujetos a auditorías del gobierno del país importador.

FIGURA 3. Inspección de una muestra de las exportaciones posibles de cebolla de Estados Unidos a México en Otay Mesa, California

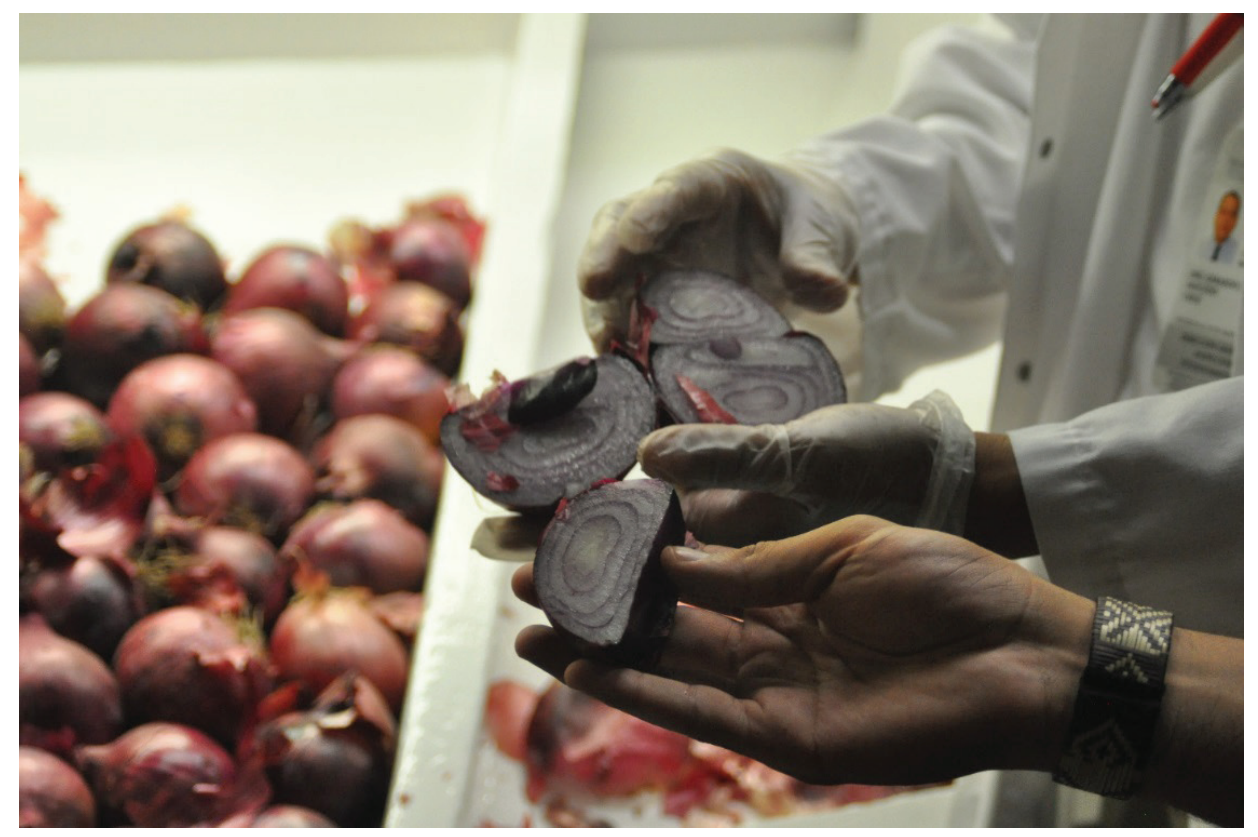

Fuente: Cortesía de Steven Zahniser, 2014.

Las importaciones de carne están sujetas a inspecciones posteriores de los gobiernos de los países importadores. Toda la carne, productos de aves y huevo procesado importados por Estados Unidos deben ser inspeccionados por el FSIS en un establecimiento de importación oficial una vez que se han llenado y enviado las formas a la Свр y se ha cumplido con los requisitos de salud animal del APHIS (USDA/FSIS, 2015b). Los establecimientos oficiales de importación usualmente se 
localizan fuera del punto de importación para aliviar la congestión en frontera. En México, las inspecciones de carne importada tienen lugar en los puntos de entrada con disponibilidad de instalaciones de frío o bien, para productos consignados a plantas TIF, en la planta TIF misma. Esta última opción descongestiona el proceso de inspección en frontera al llevar a cabo algunas acciones de inspección dentro del territorio nacional.

El Senasica está evaluando los beneficios económicos de un programa de relocalización de algunas inspecciones de las instalaciones de la aduana en puntos del interior de México. Este programa actualmente cubre 21 productos de bajo riesgo de Estados Unidos y Canadá, como leche en polvo y productos lácteos, alimento para mascotas, turba, sustituto de crema y harina de soya. De acuerdo con estimados preliminares del Senasica, el tiempo de tránsito se reduce $28 \%$ y el costo total del flete se reduce $76 \%$ en el caso de transporte ferroviario. En el caso de embarques transportados por tierra hacia la frontera y de la frontera a una aduana interior por tren, el tiempo de tránsito promedio se incrementa dos días, pero el costo total de transporte se reduce $43.5 \%$. Este programa formará parte del sisi, y la expectativa es incluir otros productos regulados por la Senasica como parte de la primera etapa del sisI.

Estados Unidos no lleva a cabo inspecciones de carme en México, y México no realiza inspecciones de las importaciones de carne en Estados Unidos; por lo tanto, se excluye la posibilidad de establecer operaciones de pre-inspección para el comercio bilateral de carne a través del programa del Ucon; sin embargo, el gobierno mexicano permite a los importadores de carne para un procesamiento posterior tener inspecciones en las plantas TIF, nuevamente para reducir la congestión en frontera.

Actualmente se han construido instalaciones privadas en los alrededores de la frontera especialmente diseñadas para servir como sitios de inspección para las importaciones mexicanas de carne, lo cual podría desincentivar la pre-inspección, ya que algunas de estas nuevas instalaciones son de gran tamaño y muy sofisticadas. El equipo de investigación llevó a cabo entrevistas con los propietarios de una de estas instalaciones en construcción en Nuevo Laredo.

\section{Identificación entomológica y laboratorios de muestreo}

Algunos de los entrevistados mencionaron la importancia de llevar a cabo el muestreo para la inspección de plagas y las pruebas de laboratorio en forma adecuada y consistente. Todas las actividades de inspección de Estados Unidos -incluyendo algunas llevadas a cabo previamente por acuerdos interinstitucionales de cooperación- fueron transferidas al DHs en 2002, y la responsabilidad para inspeccionar las importaciones agropecuarias pasó del APHIS a la СвP en 2003.

Los insectos detectados por un inspector estadounidense pueden caer en una 
de dos grandes categorías. Las plagas reportables deben ser reportadas al APHIS, mientras que las no reportables no son de interés cuarentenario. Las plagas reportables se dividen a su vez en procesables, que requieren de acciones regulatorias y pueden llevar a la detención del embarque, y las no procesables. Los embarques detenidos por la presencia de una plaga procesable requieren de cualquiera de las siguientes acciones: 1) tratamiento (como fumigación con bromuro de metilo), de tal manera que el embarque pueda ingresar en Estados Unidos; 2) reexportación, en que el embarque puede ser retornado al país de origen y podría ser exportado a un tercer país, o 3) destrucción.

Los inspectores de la СвP reciben capacitación periódica en identificación de insectos. No obstante, pueden ocurrir demoras en la inspección cuando el insecto detectado no se puede identificar de inmediato. En tal situación, el insecto se envía a un entomólogo de la oficina de Protección Vegetal y Cuarentena (Plant Protection and Quarantine, PPQ) del APHIs en el puerto de entrada. Si el entomólogo no puede identificarlo, debe enviar una imagen digital (o incluso el mismo insecto) a un entomólogo del Instituto Smithsoniano en Washington, D.C. Esto requiere de un trabajo preciso porque algunos insectos son difíciles de escanear en forma digital. Aproximadamente $10 \%$ de las detecciones de insectos enviadas al entomólogo del APHIS en el Punto de Ingreso de Mariposa requieren de la asistencia de Washington. Estas intercepciones se envían como "urgentes" y la respuesta se obtiene dentro de las siguientes 24 horas.

Las pruebas de los muestreos de importaciones de alimentos que realiza la FDA se guían por la PREDICT. Las inspecciones de alimentos de la FDA se llevan a cabo usualmente junto con las inspecciones agropecuarias de la СBP. El muestreo de los embarques tiene lugar en el punto de entrada, pero las pruebas se hacen en alguno de los laboratorios oficiales de la FDA ubicados en lugares alejados de la frontera entre México y Estados Unidos, en estados como Colorado y Arkansas. Aun con envíos nocturnos, el procesamiento de muestreo y las pruebas de laboratorio toman entre cuatro y siete días. Para reducir este tiempo, la FDA a veces despliega laboratorios móviles en puntos clave como Nogales durante la temporada alta. Varios entrevistados del área de Nogales tienen una opinión positiva de esta estrategia. De manera similar, el gobierno mexicano opera tres laboratorios móviles, en los cuales se analizan los microorganismos patógenos y los residuos tóxicos. Esta alternativa da mayor flexibilidad y capacidad de respuesta que los recursos de laboratorio.

\section{Laboratorios en México}

El Senasica tiene una red de laboratorios dedicados a la detección de plagas y enfermedades agrícolas, los cuales tienen la infraestructura necesaria para proporcionar servicios de diagnóstico y verificación en forma oportuna, confiable y de alta cali- 
dad. Los servicios son dirigidos por personal altamente especializado, con técnicas modernas y equipo de última generación. Estos recursos permiten una toma de decisiones ágil para el control y la erradicación de plagas y enfermedades de alto riesgo para los sectores agropecuario y pesquero (Sagarpa/Senasica, 2014, 2013a).

En México también existe una red de 14 Laboratorios de Diagnóstico Fitosanitario Aprobados que opera el sector privado y se localizan principalmente en la parte central del país y a lo largo de la frontera con Estados Unidos. Estos laboratorios acreditados cuentan con autorización del Senasica para llevar a cabo diagnósticos fitosanitarios de vegetales y productos de origen vegetal; proporcionan sus servicios principalmente a los productores e importadores. El país también cuenta con cuatro laboratorios acreditados y aprobados de este tipo para el diagnóstico de enfermedades de organismos acuáticos. Para las pruebas fitosanitarias llevadas a cabo por laboratorios acreditados, el importador selecciona aquel al que enviará su muestra. La mayoría de los resultados se obtienen en dos o tres días.

\section{Horas de operación}

Algunos entrevistados expresaron su interés por que los inspectores de la FDA contaran con un horario más amplio en los puntos de entrada y por una alineación de los horarios de trabajo de varias de las agencias de Estados Unidos responsables de las inspecciones agropecuarias. Los horarios de operación normales de la FDA son de 8:00 a 16:30 horas, de lunes a viernes (USHHS/FDA, 2015); la FDA también realiza inspecciones los sábados en puntos de entrada como Nogales y Otay Mesa. No fue claro en las entrevistas qué impide a los transportistas llegar en las horas normales de operación. En lugar de ello, los entrevistados aparentemente buscan mayor flexibilidad mediante más horas de operación. Algunos recomendaron que haya inspecciones agropecuarias las 24 horas del día y los siete días de la semana, es decir, todos los días del año, con la condición de que los transportistas paguen un sobreprecio por las inspecciones que se hagan fuera de los horarios normales de operación.

Los oficiales de agricultura, acuacultura y pesca de México proporcionan servicios de inspección durante los horarios establecidos en la Guía general para la certificación de mercancías reguladas por la Sagarpa, importadas con fines comerciales: - En las instalaciones localizadas en México, lunes y viernes de 9:00 a 20:00 horas, y martes, miércoles y jueves de 9:00 a 19:00 horas.

- En instalaciones localizadas en Estados Unidos, de lunes a viernes de 9:00 a 16:00 horas. El horario más reducido en las instalaciones mexicanas en Estados Unidos es para permitir a los oficiales viajar de ida y regreso desde México.

Las horas de operación para las inspecciones de trenes se especifican en el acuerdo que autoriza el cruce de ellos, y se pueden solicitar horarios fuera de servi- 
cio con antelación (Sagarpa/Senasica, 2014a). En los cruces ferroviarios fronterizos de Piedras Negras-Eagle Pass y Nuevo Laredo-Laredo, la Sagarpa opera las 24 horas del día, todos los días del año.

Así como México ha usado modelos de asociación público-privada para la construcción de nueva infraestructura, Estados Unidos los ha utilizado para ampliar los recursos disponibles para las actividades de inspección. Legislación reciente autoriza a la CBP a aceptar reembolsos de negocios y gobiernos locales para "aduanas, inmigración y procesamiento de mercancías agrícola; salarios para personal adicional; y gastos por horas extras en aeropuertos" (USDHS/CBP, 2014, traducción nuestra). Esta flexibilidad ha permitido a la СвР proporcionar más tiempo extra a sus inspectores en los puentes internacionales en El Paso, gracias al acuerdo de servicios reembolsables con el gobierno de la ciudad (Martínez, 2014). La legislación también autoriza a la СBP y la Administración General de Servicios (General Services Administration, GSA) para "aceptar donaciones de bienes muebles e inmuebles o servicios no personales para ser usados para la construcción, modificación, operación, o mantenimiento de un punto de entrada nuevo o ya existente" (USDHS/CBP, 2014, traducción nuestra).

\section{Protocolos sanitarios y fitosanitarios}

Los entrevistados recomendaron la modificación de algunos elementos de los protocolos sanitarios y fitosanitarios para facilitar el comercio de ciertos productos. Una sugerencia fue reducir la cantidad de muestras biométricas y el cortado al que se sujetan los productos frescos importados. Por ejemplo, con el aguacate hass importado por Estados Unidos de México el muestreo y cortado pueden hacerse en el campo, la empacadora y el primer punto de entrada a Estados Unidos. En febrero de 2015, USDA/APHIS (2015) publicó una propuesta de regla que permitiría que el cortado en el punto de entrada fuera a criterio del inspector, con el fin de incrementar la flexibilidad operativa de los inspectores agrícolas de la свр. Durante las visitas de campo observamos el muestreo y corte de varias frutas y hortalizas frescas llevado a cabo no solo por personal de los gobiernos de Estados Unidos y México, sino también por representantes de los compradores.

Algunos de los cambios sugeridos tienen la intención de permitir una mayor participación en el comercio bilateral, tanto en términos de los bienes comercializados como del número de empresas participantes. Por ejemplo, se sugirió un período de monitoreo más corto para el programa voluntario de certificación de Estados Unidos de caprinos y ovinos vivos. Los entrevistados también expresaron interés en protocolos sanitarios que puedan conducir a una mayor participación de productores que exporten fruta de hueso a México. 


\section{Camiones pesados: una respuesta a la congestión fronteriza y diferentes estándares}

Los investigadores han señalado el uso extensivo del sistema de carga pesada para transportar mercancías por camión a través de la frontera entre México y Estados Unidos como una fuente importante de congestión fronteriza, mayores tiempos de cruce y costos de envío más altos (Coyle, 2000; Fox, Francois \& Londoño-Kent, 2003; Prozzi, Villa, Middleton \& Warner, 2008). En contraste, varios entrevistados sugirieron que el sistema de carga es, en cierta medida, una respuesta a la congestión fronteriza y las diferencias en las normas de camiones entre Estados Unidos y México, particularmente en los estándares de peso de los remolques-tractores.

En el sistema de carga pesada, el transporte de carga por camión entre México y Estados Unidos suele requerir al menos tres vehículos: "un servicio de largo recorrido que transporta la carga de México/Estados Unidos a un lugar cercano a la frontera, un camión de transporte de corta distancia que traslada las mercancías a través de la frontera, y un tercer camión que entrega la carga hasta su destino final más allá de la zona comercial fronteriza México-Estados Unidos" (Prozzi et al., 2008, pp.1-2, traducción nuestra). El sistema de carga pesada es atractivo en su asequibilidad; el costo de los servicios proporcionados por un camión de transporte y su conductor es menor que el de servicios similares proporcionados por un camión de largo recorrido y su conductor.

Otros incentivos también motivan la carga y descarga de mercancías en la región fronteriza. En primer lugar, los transportistas pueden aprovechar la oportunidad para ajustar las cargas de peso de los camiones y acercarse al máximo permitido en jurisdicciones particulares. ${ }^{7}$ En segundo lugar, la región fronteriza ofrece la oportunidad de agregar envíos de varios proveedores a un destino específico. Tercero, con una buena cantidad de integración horizontal en el sector de logística comercial, muchos agentes mexicanos de aduanas tienen su propio agente de envío en Estados Unidos y su propio negocio de transporte de carga.

Una alternativa al sistema de carga pesada es que el camión de larga distancia de Estados Unidos o México también realice el servicio de cruce fronterizo, como se mencionó en entrevistas en las regiones de San Diego/Tijuana y Reynosa/McAllen. Otra alternativa es el transporte transfronterizo de larga distancia, como lo permite el TLCAN. En este enfoque de un solo camión de larga distancia, operado por un transportista estadounidense o mexicano, se proporciona un servicio de "puerta a

\footnotetext{
7 Las diferencias entre las regulaciones de camiones de Estados Unidos y México han sido reconocidas desde hace tiempo como una posible oportunidad para la alineación regulatoria. Por ejemplo, el difunto Robert Pastor defendió que Canadá y Estados Unidos “...elaboren normas nacionales sobre peso, seguridad y configuración del transporte por carretera y luego negocien con México sobre un solo conjunto de normas" (Pastor, 2011, traducción nuestra).
} 
puerta" desde el origen en un país hasta el destino en el otro. ${ }^{8}$ Una tercera alternativa es dedicar un remolque en lugar de un camión a proporcionar servicio puerta a puerta. En esta variante del sistema de carga pesada, el mismo remolque es arrastrado por una secuencia de diferentes camiones del origen al destino. Este enfoque es utilizado a veces por los exportadores agrícolas que están enviando un remolque completo del producto a un solo cliente.

Incluso con alternativas, el sistema de carga pesada continúa siendo el método más usado para transportar mercancías por camión a través de la frontera Estados Unidos-México. La participación fue muy baja en el Programa Piloto de Transporte Transfronterizo de Larga Distancia entre Estados Unidos y México, operado por la Administración Federal de Seguridad de Transportes del Departamento de Transportes de los Estados Unidos (U.S. Department of Transportation, Federal Motor Carrier Safety Administration, usDot/FMCSA) del 14 de octubre de 2011 al 10 de octubre de 2014. Solo 12 transportistas mexicanos tenían autoridad operativa al final del programa, aunque un transportista realizó 20,102 cruces durante este período y otro cruzó 5.528 veces (USDOT/FMCSA, 2014). ${ }^{9}$

\section{Nuevas instalaciones de transporte y rutas de envío}

Algunos entrevistados indicaron que los servicios ferroviarios, en particular los sistemas camión-ferrocarril, no han sido del todo utilizados en el envío de productos agropecuarios. Si bien el transporte intermodal se utiliza en otras industrias, el sector agroalimentario todavía no lo hace por completo debido a las restricciones reglamentarias y a la escala y ubicación de la infraestructura fronteriza. Además, el volumen de las exportaciones que ingresan en Estados Unidos por el Distrito Aduanal de Laredo está creciendo más rápido que las exportaciones que entran por los Distritos Aduanales de Nogales o de San Diego, lo que significa un cambio hacia los puertos de Texas en términos absolutos y proporcionales. Estos desarrollos pueden requerir nuevos protocolos de logística e inspección para acompañar cualquier nueva instalación de transporte y acomodar los cambios en el volumen de comercio entre los puertos de entrada.

La propuesta del Agroparque AARC, un parque agroindustrial propuesto por la Asociación de Agricultores del Río Culiacán (AARC), busca contar con conexiones intermodales camión-ferrocarril. Incluiría un área para cargar y descargar contenedores de frutas, hortalizas y productos varios; una zona de carga y descarga de

$8 \quad$ Las disposiciones del TLCAN para el transporte transfronterizo de camiones entre Estados Unidos y México no se aplican a las rutas exclusivamente dentro de cada país.

9 En enero de 2015, USDOT/FMCSA (2015) anunció que aceptaba solicitudes de transportistas mexicanos para llevar a cabo operaciones de transporte transfronterizo de larga distancia. 
cereales, y un almacén aduanero donde podrían realizarse inspecciones sanitarias y fitosanitarias. La instalación propuesta abarcaría aproximadamente 50 hectáreas y estaría cerca de Culiacán, Sinaloa, la capital del principal estado productor de frutas y hortalizas de México. Una línea de ferrocarril, que será utilizada por trenes con vagones intermodales, se extendería hacia el norte desde sus instalaciones hasta Nogales o Tucson, proporcionando así una alternativa a los camiones para transportar las exportaciones de productos a Nogales (Asociación de Agricultores de Río Culiacán, 2014). Se ha elaborado un plan ejecutivo para esta instalación y una evaluación preliminar del plan indica que el proyecto es factible. El siguiente paso es asegurar inversionistas para el mismo.

La velocidad, más que el costo, parece ser el principal desafío para que el ferrocarril se convierta en una alternativa viable para el transporte de productos en el interior de Estados Unidos. En 2014, algunos transportistas experimentaron con el ferrocarril para enviar sandías de Nogales a Jessup, Maryland. El viaje duró 22 días (Prendergast, 2014). En contraste, el tiempo de conducción entre estas dos ciudades es de aproximadamente 35 horas.

Datos comerciales indican un mayor uso de puntos del este como Laredo y Weslaco, Texas, para importar frutas y hortalizas frescas o congeladas de México (gráfica 2). En los tres principales distritos aduaneros para estas importaciones - Laredo, Nogales y San Diego- aumentaron las importaciones en la última década. Pero las importaciones en el distrito de Laredo (que incluye Laredo y Weslaco, entre otros puertos de entrada) crecieron a un ritmo más rápido. Como resultado de ello, la participación de Laredo en estas importaciones aumentó de $31 \%$ a 48 \% entre 2004 y 2015, mientras que la participación de Nogales disminuyó de 45 \% a 31 \% y la de San Diego disminuyó de $21 \%$ a $15 \%$.

Varios factores causales explican este cambio geográfico. Primero, en 2013, el gobierno mexicano inauguró la carretera federal 40D entre Mazatlán y Durango. Esta nueva carretera de peaje incluye una serie de proyectos de infraestructura - entre ellos 63 túneles y 32 puentes - diseñados para acelerar el tránsito por el accidentado terreno de las montañas de la Sierra Madre. Tal vez la joya de la corona entre estas obras públicas es el puente Baluarte (figura 4). Como resultado de esto, el recorrido de extremo a extremo en esta carretera de peaje toma alrededor de dos horas y media, mucho menos que el lapso de seis a ocho horas en la antigua carretera federal 40 (Durango-Mazatlán Hwy 40D, 2014).

En segundo lugar, la producción de frutas y hortalizas en el centro y el oriente de México se ha expandido más rápidamente que en el occidente del país. Según datos del Servicio de Información Agroalimentaria y Pesquera (Sagarpa/siap, 2016), la producción promedio anual de frutas, hortalizas y legumbres secas en México aumentó 22.3 \% de 2001 a 2003 y de 2012 a 2014. Los diez estados mexicanos con los mayores aumentos porcentuales de producción durante este período (Quintana 
Roo, Querétaro, Jalisco, Morelos, Tamaulipas, Sonora, Aguascalientes, Michoacán, Tlaxcala y Coahuila), excepto Sonora, están más cerca de Laredo, Texas, que de Nogales, Arizona. Estos diez estados, menos Sonora, representaron el $28 \%$ de la producción mexicana de frutas, hortalizas y legumbres secas de 2012 a 2014, en comparación con el $24 \%$ de 2001 a 2003.

GRÁFICA 2. Importaciones Estados Unidos de frutas y legumbres desde México, frescas o congeladas, por distrito aduanal estadounidense, 2004-2015.

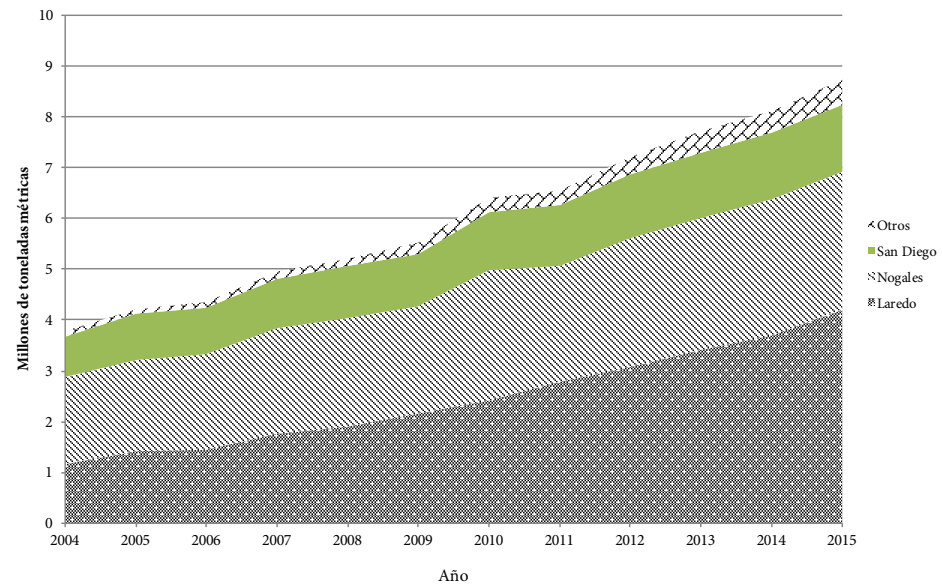

Fuente: U.S. Department of Commerce, Census Bureau, Foreign Trade Statistics, citado por USDA/FAS (2016).

FIGURA 4. Puente Baluarte, en la nueva carretera de peaje de Sinaloa a Durango

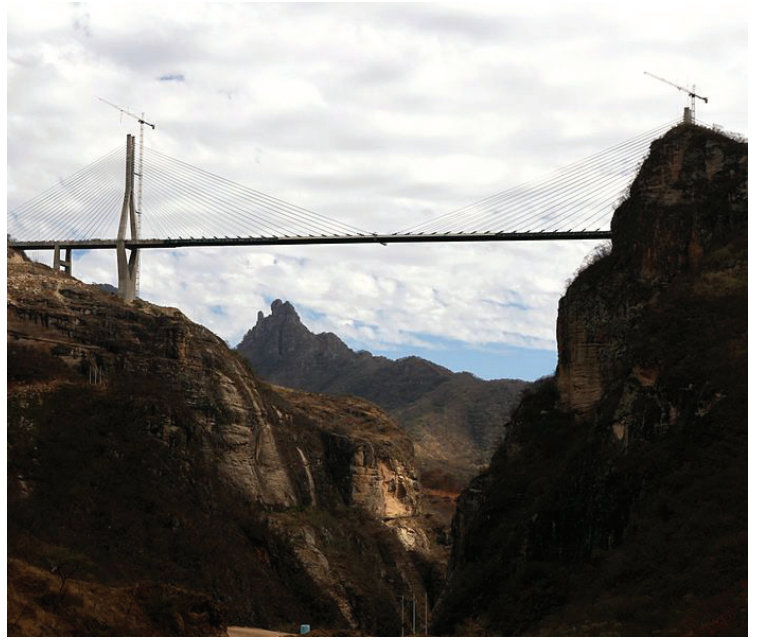

Fuente: panza.rayada (2012). 
Varios entrevistados en el área de Nogales expresaron su preocupación porque algunos camiones mexicanos son detenidos e inspeccionados varias veces por autoridades federales y estatales de camiones de Estados Unidos. Las autoridades mexicanas proponen establecer un programa piloto entre Estados Unidos y México que incluya los siguientes elementos:

- Inspección previa de camiones en México y reconocimiento por parte de Estados Unidos de las inspecciones físicas y mecánicas de remolques de tractores hechas antes del cruce fronterizo.

- Uso amplio de la tecnología para compartir información con la FMCSA de manera simultánea.

- Un enfoque en las principales fallas mecánicas que causan violaciones ante la FMCSA (frenos, suspensión, neumáticos, luces, etcétera).

- Establecimiento de un memorando de reconocimiento mutuo entre México y Estados Unidos para estandarizar las inspecciones de vehículos comerciales mexicanos.

\section{Integridad de los embarques}

Varios distribuidores e inspectores de productos cárnicos expresaron su preocupación en torno a la integridad de los embarques de carne en su trayecto desde las plantas productoras hasta la frontera. En algunos casos los embarques son rechazados por los inspectores de gobierno o por personal de control de calidad de las empresas privadas debido a la presencia de productos derramados o echados a perder.

En México, las inspecciones militares en Puestos de Control Estratégico (Precos) presentan un desafío adicional para mantener el flujo oportuno del comercio y la integridad de los envíos agropecuarios destinados a la exportación. Estas inspecciones inevitables a veces son precedidas por largos tiempos de espera y constituyen otra área de mejora potencial. La Sagarpa ha invertido recursos junto con la Secretaría de la Defensa Nacional (Sedena) para reducir el impacto logístico de estas inspecciones. Las recientes inversiones de la Sagarpa en los puestos de control en Querobabi, Sonora, y La Coma, Tamaulipas, incluyen la instalación de tecnologías de inspección no intrusiva y la capacitación del personal sobre la forma de evitar la contaminación de mercancía y no poner en peligro la seguridad alimentaria.

\section{Áreas de oportunidad}

Con base en la información proveniente de las entrevistas y de otras fuentes de información pública, se detectaron seis áreas de oportunidad para hacer más ágil el comercio agropecuario entre México y Estados Unidos, las cuales comprenden: 
- Aspectos relacionados con el sector agropecuario respecto al tránsito y la inspección en la frontera.

- Sistemas de predesgacho y de preinspección e instalaciones de inspección conjunta.

- Un mayor desarrollo de los sistemas de inspección basados en el riesgo.

- Anticipación de nuevas instalaciones de transporte y nuevas rutas de envío.

- Actividades complementarias a las Ventanillas Únicas.

- Creación de vías formales para la innovación reguladora.

\section{Aspectos relacionados con el sector agropecuario respecto}

al tránsito y la inspección en la frontera

El proceso de cruce e inspección en la frontera es crítico en el tránsito de bienes agropecuarios desde su origen hasta su destino. Los problemas en este punto pueden obstaculizar el flujo comercial de varias maneras: elevando los costos de transacción, reduciendo la velocidad del tránsito de los bienes e incluso incrementando las pérdidas debidas al desperdicio de productos. Al mismo tiempo, la certificación e inspección de las importaciones agropecuarias son necesarias y de gran utilidad para validar que estas pueden ser consumidas en forma segura, y no representan un riesgo inaceptable para los recursos animales y vegetales del importador.

El gobierno y el sector privado desempeñan un papel importante para que este proceso funcione adecuadamente. El gobierno debe tener la capacidad de conducir las inspecciones en forma consistente, tanto en tiempo como en los diferentes puertos de entrada, para impedir el arbitraje de puertos ${ }^{10}$ y asegurar que aquellas se realicen bajo los estándares adecuados. En algunas entrevistas salieron a relucir antiguos problemas con la consistencia de las inspecciones para algunos productos particulares, como las hortalizas asiáticas destinadas al mercado estadounidense y las pieles de ganado dirigidas a México. Tales inconsistencias deben ser atendidas mediante la supervisión y el monitoreo directo de los inspectores, o bien con la organización de seminarios de capacitación específicos para estos. Asimismo, para acabar con malos entendidos sería de gran utilidad un mayor esfuerzo de ambos gobiernos para explicar a la industria lo que se está haciendo para mejorar la consistencia de las inspecciones. Al mismo tiempo, las ciudades fronterizas compiten entre ellas por atraer la construcción de obras de infraestructura y aumentar la actividad comercial, por lo que los oficiales que se encuentran en cada puerto de entrada adaptan a discreción sus operaciones a las condiciones locales.

10 Por arbitraje de puertos se entiende el proceso en el que el importador selecciona estratégicamente los puntos y tiempos de entrada para disminuir significativamente la probabilidad de que se detecten embarques que no cumplan con los requisitos de importación. 
Uno de los retos para el sector público es encontrar el balance apropiado entre la cantidad de personal, el mejoramiento del marco regulatorio basado en el riesgo y el uso de los sistemas de tecnología de la información. El personal debe poseer las habilidades y los conocimientos especializados - como la capacidad de identificar insectos, recolectar y hacer pruebas con muestras- y estar familiarizado con los estándares de los productos agropecuarios para llevar a cabo las inspecciones. En el caso de las oficinas de inspección en Estados Unidos, se nos informó que varias estaban a la espera de personal recientemente contratado, aunque consideraban que la cantidad era suficiente para cumplir con su trabajo. En México, el gobierno ha incrementado su capacidad a través de las actividades de terceros en las Unidades de Verificación y la autorización de la SHCP para contratar personal en forma temporal. Además, ambos gobiernos necesitan tener bases de información actualizadas para regular el comercio agropecuario. Ejemplo de ello son los listados de plantas autorizadas para la exportación de carne o la identificación precisa de los ranchos donde se producen las hortalizas comerciadas. Este punto destacó especialmente en las conversaciones con el personal de las autoridades regulatorias en México y Estados Unidos.

El sector privado, por su parte, requiere de la documentación completa y precisa acerca de las características de los productos comerciados entre uno y otro país. Esta es indispensable para pasar la inspección y el adecuado funcionamiento de las herramientas de filtrado basado en el riesgo, como el modelo PREDICT de la FDA; además de ser de gran utilidad para el rastreo de productos en las investigaciones relacionadas con la aparición repentina de enfermedades transmitidas por alimentos. Adicionalmente, el sector privado debe asegurarse de que los productos agropecuarios comerciados entre ambos países permanezcan en óptimas condiciones desde el origen hasta su destino. Estas labores recaen sobre numerosas empresas particulares, pero es necesario reconocer que los problemas de una empresa pueden afectar al resto de los actores del comercio internacional. Por ejemplo, un camión cargado con productos rechazados aumenta la congestión del tráfico y desvía la atención de los inspectores, lo que les impide atender otros cargamentos que sí cumplen con las normas regulatorias. Por esta razón, las actividades encaminadas a mejorar y actualizar el conocimiento de los exportadores agropecuarios en materia de requisitos regulatorios y su cumplimiento en México y Estados Unidos (por ejemplo, a través de cursos de actualización) podrían generar importantes beneficios para todos los participantes en el comercio internacional.

\section{Sistemas de predesgacho y de preinspección e instalaciones de inspección conjunta}

El diseño de las operaciones de inspección en México y Estados Unidos es reflejo de un enfoque creativo que ha buscado reubicar algunos de sus aspectos fuera de la frontera. Por ejemplo, México preautoriza sus importaciones de frutas y vegetales 
de Estados Unidos por medio de concesiones privadas situadas en el lado estadounidense. Otros ejemplos incluyen el programa estadounidense de preautorización para mangos irradiados y las instalaciones conjuntas en Tijuana, México, que actualmente efectúan una prueba piloto para la preinspección de las importaciones de frutas y hortalizas provenientes de México. Instalaciones similares podrían considerarse en otros puntos de entrada de embarques agropecuarios destinados al norte o al sur. La preinspección podría hacerse extensiva a la inspección de tractocamiones usados en las operaciones de distancia corta que caracterizan el tráfico interfronterizo, algo que algunos actores del lado mexicano han sugerido. Un acuerdo de esta índole reduciría el número de paradas de los conductores mexicanos durante los trayectos de corto alcance en el lado estadounidense de la frontera.

\section{Un mayor desarrollo de los sistemas de inspección basados en el riesgo}

Los gobiernos de México y Estados Unidos siguen desarrollando, operando y afinando los sistemas de inspección basados en el riesgo, como el NARP, PREDICT, SISI y Ucon. Un mayor acercamiento con la industria para explicarle el funcionamiento de estos sistemas y la forma en que la operación de las empresas puede mejorar mediante su uso adecuado sería de gran utilidad para promover estos esfuerzos. En primer lugar, ayudaría a disipar las ideas erróneas en torno a estos sistemas. En segundo lugar, las empresas cuyos cargamentos están sujetos a tales inspecciones estarían mejor preparadas para proporcionar la información completa y precisa que se requiere para su adecuado funcionamiento. Esto aseguraría que los riesgos asociados con cada cargamento en particular sean calificados apropiadamente, en beneficio tanto de comercializadores como de las autoridades regulatorias. En tercer lugar, un mayor acercamiento podría estimular al sector privado a sugerir nuevas formas de mejorar la efectividad de los sistemas de inspección actualmente en marcha.

\section{Anticipación de nuevas instalaciones de transporte y nuevas rutas de envío}

La construcción de nueva infraestructura de transporte y el desarrollo de nuevas rutas comerciales hacia el interior inevitablemente afectarán la demanda de servicios de inspección, lo que conducirá a un incremento desproporcionado del comercio agroalimentario en términos de variedad de productos, puertos de entrada y países exportadores. Las autoridades de ambos países pueden anticiparse a este crecimiento adaptando sus operaciones fronterizas a los nuevos patrones comerciales. En particular, los dos gobiernos pueden empezar a avanzar en el desarrollo logístico y los protocolos de inspección que serán necesarios en las nuevas instalaciones, así como estar preparados para los posibles cambios en los volúmenes de carga que experimentarán los distintos puertos de entrada. 


\section{Actividades complementarias a las Ventanillas Únicas}

Los gobiernos de México y Estados Unidos se han comprometido a afinar e incrementar la operación de sus sistemas de Ventanilla Única. Este compromiso representa la oportunidad de implementar una serie de actividades complementarias diseñadas para hacer un uso más completo y eficiente de tales sistemas.

En primer lugar, los dos gobiernos podrían utilizar sus sistemas de Ventanilla Única como plataformas para agilizar y simplificar los requisitos administrativos del comercio bilateral agropecuario. Este esfuerzo podría incluir no solo completar el esfuerzo actual para instituir los certificados electrónicos para todos los productos agropecuarios, sino la consolidación o eliminación de algunos tipos de documentos y un mayor periodo de validez para otros. La convergencia práctica de ambos sistemas de Ventanilla Única facilitaría el intercambio de información y eliminaría las diferencias innecesarias en los respectivos sistemas regulatorios. Los esfuerzos para agilizar y simplificar los requisitos administrativos pueden enriquecerse con opiniones y sugerencias del sector privado.

En segundo lugar, cada gobierno podría organizar seminarios para capacitar al sector privado en la navegación de los sistemas de Ventanilla Única. Aunque la Ventanilla Única mexicana se encuentra en operación desde 2012, el sistema estadounidense (ACE) está programado para entrar en operación a finales de 2016, pues en 2015 se cumplieron los plazos intermedios establecidos por la ley para su uso obligatorio.

\section{Creación de vías formales para la innovación reguladora}

Finalmente, la creación de un mecanismo formal de retroalimentación en los temas relacionados con los procesos regulatorios que caracterizan al comercio agropecuario bilateral sería de gran valor para institucionalizar y hacer realidad algunas de las ideas identificadas por las entrevistas a nivel micro, agilizándolo así de manera significativa. La creación de este mecanismo aseguraría la consideración de un abanico de propuestas más amplio, particularmente las que se originan en el sector privado.

Varias de estas ideas requerirían de nuevos enfoques en los procedimientos y las inspecciones de frontera. Por ejemplo, muchos de los entrevistados mencionaron que existen oportunidades no aprovechadas para reducir el tiempo de muestreo y examen de los cargamentos agropecuarios. Si los laboratorios estuviesen más cerca de la frontera se reduciría el tiempo que transcurre entre la toma de la muestra y el examen. La FDA tiene ya en operación varios laboratorios móviles y los coloca en puertos como Nogales durante la temporada alta de importación. El uso de laboratorios certificados y oficialmente reconocidos, operados por empresas privadas o 
instituciones académicas en localidades cercanas a la frontera, es otro posible enfoque, ya adoptado por el gobierno mexicano para cubrir algunas de sus necesidades de verificación. Adicionalmente, la incorporación de nuevas tecnologías podría reducir la cantidad de tiempo necesaria para completar las pruebas, e incluso podría hacer posible que estas se lleven a cabo en el mismo puerto de entrada.

Equiparar los horarios de inspección en la frontera y alinearlos lo más posible con los del sector privado sería, de acuerdo con los entrevistados, una innovación muy bienvenida. Algunos de ellos contemplan la posibilidad de una frontera abierta al comercio agropecuario las 24 horas del día, los siete días de la semana. Sin embargo, se debe destacar que mantener una frontera abierta en forma permanente presenta ventajas y desventajas en términos de costos, personal y calidad de las inspecciones.

\section{Referencias}

Asociación de Agricultores de Río Culiacán (AARC) (2014, 25 de julio). AgroParque AARC. Presentación de PowerPoint.

Burfisher, M., House, R. \& Langley, S. (1992). Free trade impacts on U.S. and Southern agriculture. Southern Journal of Agricultural Economics, 24(1), 61-78.

Coyle, W. (2000, septiembre). Transportation bottlenecks shape U.S.-Mexico food and agricultural trade. U.S. Department of Agriculture, Economic Research Service, Agricultural Outlook, 24-31. Recuperado de http://pdic.tamu.edu/pdicdata/pdfs/ao274h.pdf

Dibble, S. (2013, 2 de enero). U.S., Mexico to open joint inspection stations. San Diego Union-Tribune. Recuperado de http://www.utsandiego.com/news/2013/jan/02/ us-mexico-open-joint-inspection-stations/?\#article-copy

Dibble, S. (2016, 12 de enero). U.S., Mexico launch joint inspections in Tijuana. San Diego Union-Tribune. Recuperado de www.sandiegouniontribune.com/news/2016/jan/12/ otay-cargo-facility-streamlines-produce-shipments

Durango-Mazatlán Hwy 40D (2014, mayo). International Travel News, 4. Recuperado de http://www.intltravelnews.com/2014/05/durango-mazatl\%C3\%A1n-hwy-40d

Fox, A., Francois, J. \& Londoño-Kent, P. (2003, 30 de abril). Measuring border crossing costs and their impact on trade flows: the United States-Mexican trucking case. Ponencia presentada en la 6th Annual Conference on Global Economic Analysis, The Hague, The Netherlands. Recuperado de https://www.gtap.agecon.purdue.edu/resources/download/1492.pdf

Gobierno de la República (2016). Ventanilla Única: sobre la vU: operación. Página web. Recuperado de https://www.ventanillaunica.gob.mx/vucem/SobreVU/Operacion/index.htm

Hummels, D. \& Schaur, G. (2012). Time as a trade barrier. National Bureau of Economic Research, Working Paper No. 17758. Recuperado de http://www.krannert.purdue. edu/faculty/hummelsd/research/time\%20as\%20a\%20trade\%20barrier.pdf 
Link, J. \& Zahniser, S. (1999). NAFTA. U.S. Department of Agriculture, Economic Research Service, International Agricultural Trade Reports, Situation and Outlook Series, WRS99-1. Recuperado de http://usda.mannlib.cornell.edu/usda/ers/WRS//1990s/1999/ WRS-08-31-1999_NAFTA.pdf

Marizco, M. (2010). Arizona pulls produce inspectors out of Mexico. Fronteras: the changing Americas desk. Recuperado de http://www.fronterasdesk.org/content/arizona-pulls-produce-inspectors-out-mexico

Martínez, A. (2014, 24 de enero). El Paso city officials, СвP sign agreement to reduce bridge wait times. El Paso Times. Recuperado de http://www.elpasotimes.com/news/ ci_24982324/city-officials-cbp-sign-agreement-reduce-bridge-wait

Novy, D. (2013). Gravity redux: measuring international trade costs with panel data. Economic Inquiry, 51(1), 101-121. Recuperado de http://onlinelibrary.wiley.com/ doi/10.1111/j.1465-7295.2011.00439.x/pdf

panza.rayada (2012, 10 de marzo). Puente Baluarte. Foto.

Pastor, R. (2011). Beyond NAFTA: the emergence and future of North America. En Yasmeen, A.-L., Jhappan, R. \& François. R. (eds.), Politics in North America: redefining continental relations (pp. 461-476). Peterborough, Ontario: Broadview Press.

Prendergast, C. (2014). Train takes local produce 'back to the future'. Nogales International (12 de agosto, versión actualizada). Recuperado de http://www.nogalesinternational. com/news/train-takes-local-produce-back-to-the-future/article_68178c08-e5b211e3-95f6-001a4bcf887a.html

Prozzi, J., Villa, J. Middleton, D. \& Warner, J. (2008). Integration and consolidation of border freight transportation data for planning applications and characterization of NAFTA truckloads for aiding in transportation infrastructure management: second year. Report No 0-5339-2, Project No. 0-5339. Recuperado de http://tti.tamu.edu/documents/0-5339-2.pdf

Secretaría de Agricultura, Ganadería, Desarrollo Rural, Pesca y Alimentación (Sagarpa) (2015, 16 de abril). Acuerdo por el que se establecen los lineamientos generales para la autorización, operación y, en su caso, reconocimiento de los establecimientos para inspección y verificación de mercancías reguladas por la Secretaría de Agricultura, Ganadería, Desarrollo Rural, Pesca y Alimentación, a través del Servicio Nacional de Sanidad, Inocuidad y Calidad Agroalimentaria, en operaciones de comercio exterior. Diario Oficial de la Federación. Recuperado de http://www.dof.gob.mx/nota_detalle. php? codigo $=5389055 \&$ fecha $=16 / 04 / 2015$

Secretaría de Agricultura, Ganadería, Desarrollo Rural, Pesca y Alimentación Servicio Nacional de Sanidad, Inocuidad y Calidad Agroalimentaria (Sagarpa/Senasica) (2013a, 23 de diciembre). Diagnóstico fitosanitario. Recuperado de http://www.senasica.gob. $\mathrm{mx} /$ ?id=3210

Secretaría de Agricultura, Ganadería, Desarrollo Rural, Pesca y Alimentación Servicio Nacional de Sanidad, Inocuidad y Calidad Agroalimentaria (Sagarpa/Senasica) (2013b, 
23 de diciembre). Usuario Confiable (Ucon) y Preguntas frecuentes. Recuperado de http://www.senasica.gob.mx/?id=5010 y http://www.senasica.gob.mx/?id=5011, respectivamente.

Secretaría de Agricultura, Ganadería, Desarrollo Rural, Pesca y Alimentación Servicio Nacional de Sanidad, Inocuidad y Calidad Agroalimentaria (Sagarpa/Senasica) (2014a, 6 de febrero). Guía de Importación General. Recuperado de http://www.senasica.gob. $\mathrm{mx} /$ default.asp?id=3779 (13 de enero de 2016).

Secretaría de Agricultura, Ganadería, Desarrollo Rural, Pesca y Alimentación Servicio Nacional de Sanidad, Inocuidad y Calidad Agroalimentaria (Sagarpa/Senasica) (2014b). Laboratorios. Página web. Recuperado de http://www.ncacbsa.org/events/event_details.asp? $\mathrm{id}=695709$ \&group=

Secretaría de Agricultura, Ganadería, Desarrollo Rural, Pesca y Alimentación Servicio Nacional de Sanidad, Inocuidad y Calidad Agroalimentaria (Sagarpa/Senasica) (2015, 6 de julio). Colaboran Sagarpa y USDA para agilizar comercio bilateral seguro de productos agroalimentarios. Nota informacional. Recuperado de http://www.senasica. gob.mx/?IdNot=2093

Secretaría de Agricultura, Ganadería, Desarrollo Rural, Pesca y Alimentación Servicio de Información Agroalimentaria y Pesquera (Sagarpa/siaP) (2016). Sistema de Información Agroalimentaria de Consulta (Siacon). Banco de datos. Recuperado de http:// www.siap.gob.mx/optestadisticasiacon2012parcialsiacon-zip/

Servicio de Administración Tributaria (sAT) (2015). Ventanilla Única. Sitio web. https:// www.ventanillaunica.gob.mx/vucem/index.htm

U.S. Department of Agriculture Animal and Plant Health Inspection Service (USDA/APHIS) (2014, mayo). Import requirements for mango fruit from Mexico irradiated in Mexico arriving into all U.S. Ports. Recuperado de http://www.aphis.usda.gov/import_export/ plants/manuals/ports/downloads/FAVIR/mx_mango_t105a1.pdf

U.S. Department of Agriculture Animal and Plant Health Inspection Service (UsDA/APHIs). (2015a). Mexican Hass Avocado Import Program. Federal Register, 80(32), 8561-8564. Recuperado de https://www.federalregister.gov/articles/2015/02/18/2015-03289/mexican-hass-avocado-import-program

U.S. Department of Agriculture Animal and Plant Health Inspection Service (USDA/APHIS) (2015b, 19 de mayo). Preclearance activities. Página web. Recuperado de https://www. aphis.usda.gov/aphis/ourfocus/planthealth/import-information/sa_preclearance/ ct_preclearance_activities

U.S. Department of Agriculture Food Safety and Inspection Service (USDA/ASIS) (2015a, 16 de abril). Export requirements for Mexico. Página web. Recuperado de http:// www.fsis.usda.gov/wps/portal/fsis/topics/international-affairs/exporting-products/ export-library-requirements-by-country/Mexico

U.S. Department of Agriculture Food Safety and Inspection Service (USDA/ASIS) (2015b, 24 de marzo). Checklist for importing meat, poultry and processed egg products. Pá- 
gina web. Recuperado de http://www.fsis.usda.gov/wps/portal/fsis/topics/international-affairs/importing-products/import-checklist

U.S. Department of Agriculture Food Safety and Inspection Service (USDA/ASIS) (2015c, 12 de mayo). Pathogen reduction - Salmonella and Campylobacter performance standards verification testing. Recuperado de http://www.fsis.usda.gov/wps/wcm/ connect/b0790997-2e74-48bf-9799-85814bac9ceb/28_IM_PR_Sal_Campy.pdf?MO$\mathrm{D}=\mathrm{AJPERES}$

U.S. Department of Agriculture Foreign Agricultural Service (USDA/FAs) (2016). Global Agricultural Trade System. Banco de datos. Recuperado de http://apps.fas.usda.gov/ gats/default.aspx

U.S. Department of Commerce, Census Bureau (2016, 12 de febrero). Foreign trade: trade in goods with Mexico. Página web. Recuperado de http://www.census.gov/foreign-trade/balance/c2010.html

U.S. Department of Commerce, Bureau of Economic Analysis (2016, 28 de abril). National data: GDP \& personal income. Banco de datos. Recuperado de http://www.bea.gov/ iTable/index_nipa.cfm

U.S. Department of Health and Human Services Food and Drug Administration (UsHHS/ FDA) (2014a, 22 de diciembre). Predict. Página web. Recuperado de http://www.fda. gov/ForIndustry/ImportProgram/ucm172743.htm

U.S. Department of Health and Human Services Food and Drug Administration (UsHHs/ FDA) (2014b, febrero). Predictive risk-based evaluation for dynamic import compliance targeting (PREDICT). Presentación. Recuperado de http://www.fda.gov/downloads/ ForIndustry/ImportProgram/UCM310772.pdf

U.S. Department of Health and Human Services Food and Drug Administration (UsHHs/ FDA) (2015). Southwest Import District. January. Recuperado de http://www.fda.gov/ downloads/ForIndustry/ImportProgram/UCM319687.pdf

U.S. Department of Health and Human Services Food and Drug Administration, Division of Import Operations and Policy (UshHs/FdA/DIOP) (2012, 27 de julio). Predict Fact Sheet. Recuperado de http://www.fda.gov/downloads/ForIndustry/ImportProgram/ UCM316476.pdf

U.S. Department of Homeland Security Customs and Border Protection (UsDhs/Cвp) (2014a). National Agriculture Release Program (NARP). Página web. Recuperado de http://www.cbp.gov/border-security/protecting-agriculture/narp

U.S. Department of Homeland Security Customs and Border Protection (USDHS/CBP) (2014b, Septiembre). Preclearance expansion: fiscal year 2015 Guidance for prospective applicants. Recuperado de http://www.cbp.gov/sites/default/files/documents/ Final\%20Preclearance\%20Guidance_092014.pdf

U.S. Department of Homeland Security Customs and Border Protection (USDHs/CBP) (2015a). ACE - Automated Commercial Environment technical information. Sitio web. Recuperado de http://www.cbp.gov/trade/ace 
U.S. Department of Homeland Security Customs and Border Protection (USDHs/CBP) (2015b). Preclearance locations. Página web. Recuperado de http://www.cbp.gov/border-security/ports-entry/operations/preclearance

U.S. Department of Homeland Security Customs and Border Protection (UsDHS/CBP) (2016a). The ACE basics: Document image system. Publication No. 1138-1015. Recuperado de https:/www.cbp.gov/sites/default/files/documents/ACE\%20Basics\%20-\%20DIS_0.pdf

U.S. Department of Homeland Security Customs and Border Protection (UsDHs/CBP) (2016b, 14 de octubre). Automated commercial environment: deployment schedule. Página web. Recuperado de https://www.cbp.gov/sites/default/files/assets/documents/2016-Oct/ACE\%20Development\%20and\%20Deployment\%20Schedule\%20 -\%20October\%2014\%202016_0.pdf

U.S. Department of Homeland Security Customs and Border Protection (UsDHs/CBP) (2016c, 12 de enero). Свр Commissioner inaugurates cargo Pre-Inspection Program Pilot at Mesa de Otay. Comunicado de prensa nacional. Recuperado de https://www. cbp.gov/newsroom/national-media-release/2016-01-12-000000/cbp-commissioner-inaugurates-cargo-pre-inspection

U.S. Department of Transportation Federal Highway Administration (USDot/FHA) (2013). Freight management and operations: Commercial Vehicle Size and Weight Program. Página web. Recuperado de http://ops.fhwa.dot.gov/Freight/sw/overview/index.htm

U.S. Department of Transportation Federal Motor Carrier Safety Administration (usdot/ FMCSA) (2014). U.S.-Mexico Cross-Border Trucking Pilot Program Carrier Information. Página web. Recuperado de http://www.fmcsa.dot.gov/international-programs/ us-mexico-cross-border-trucking-pilot-program-data\#with-operating-authority

U.S. Department of Transportation Federal Motor Carrier Safety Administration (USDOT/ FMCSA) (2015). Acceptance of applications for Mexican-domiciled long-haul operations. Federal Register, 80(10), 2179.

U.S.-Mexico High-Level Regulatory Cooperation Council (HLRCC) (2013, 15 de agosto). U.S.-Mexico High-Level Regulatory Cooperation Council: Progress report to leaders. Recuperado de http://www.trade.gov/hlrcc/

Wilkinson, F. (2010, 11 de noviembre). UPDATED: Arizona suspends produce inspections in Mexico. The Packer. Recuperado de http://www.thepacker.com/fruit-vegetable-news/ updated_arizona_suspends_produce_inspections_in_mexico_122129324.html

Wilson, C. (2015). Optimizing border ports of entry to strengthen regional competitiveness -infrastructure and management. En Lee, E. \& Wilson, C. (eds.), The U.S.-Mexico border economy in transition. Washington: Woodrow Wilson Center for International Scholars. Recuperado de http://www.wilsoncenter.org/sites/default/files/Border Economy_Transition_Wilson_Lee\%20\%282\%29.pdf

World Customs Organization (2015). Single Window information store. Sitio web. Recuperado de http://www.wcoomd.org/en/topics/facilitation/activities-and-programmes/ single-window/single-window.aspx 
Zahniser, S., Herrera Moreno, A., Calderón Ruanova, A., Angadjivand, S., Calderón Elizalde, F., Calvin, L., López Amador, C., López López, N. \& Valdés Ramos, J. (2016, 22 de agosto). Opportunities for making U.S.-Mexico agricultural trade more agile. U.S. Department of Agriculture, Economic Research Service, Economic Information Bulletin No. EIB-160, http://www.ers.usda.gov/publications/eib-economic-information-bulletin/eib-160.aspx 